\title{
LDL apheresis in a woman with severe heterozygous familial hypercholesterolemia. Late, but not too late
}

Agnieszka Mickiewicz ${ }^{1}$, Marcin Fijałkowski ${ }^{1}$, Andrzej Rynkiewicz ${ }^{1}$, Grzegorz Raczak ${ }^{2}$, Marcin Gruchała ${ }^{1}$

${ }^{1}$ First Department of Cardiology, Medical University of Gdansk, Gdansk, Poland ${ }^{2}$ Department of Electrocardiology, Medical University of Gdansk, Gdansk, Poland

Submitted: 7 April 2014

Accepted: 17 April 2014

Arch Med Sci 2015; 11, 6: 1352-1353

DOI: $10.5114 /$ aoms.2015.56363

Copyright @ 2015 Termedia \& Banach

Familial hypercholesterolemia (FH) is an under-recognized and undertreated common lipid metabolism disorder [1, 2]. Early and intensive treatment reduces consequent mortality from coronary heart disease [3, 4]. A promising tool for retarding or arresting the atherosclerotic process in hypercholesterolemic patients refractory to maximally tolerated pharmacotherapy is LDL apheresis [5, 6].

We present the case of a 44-year-old woman with $\mathrm{FH}$, who was admitted to our hospital with myocardial infarction of the anterior wall. She was diagnosed with heterozygous familial hypercholesterolaemia at the age of 41, based on clinical criteria of the Dutch Lipid Network-WHO. The diagnosis was established as "definite" FH equal to premature coronary artery disease (CAD) and high LDL cholesterol concentrations before lipid-lowering treatment $(417 \mathrm{mg} / \mathrm{dl})$. DNA analysis also confirmed a mutation in exon 8 of the LDL receptor gene (p.G373).

Her medical history from the last three years prior to admission documented that she had recurrent acute coronary syndromes. Most of these were cased by stent thrombosis (5 ST-elevation myocardial infarction (STEMI), 2 non-ST-elevation myocardial infarction (NSTEMI) and 2 cases of unstable angina).

\author{
Corresponding author: \\ Agnieszka Mickiewicz \\ First Department \\ of Cardiology \\ Medical University of Gdansk \\ 7 Debinki St \\ 80-952 Gdansk, Poland \\ Phone: +48502639051 \\ Fax: +48 3461201 \\ E-mail: \\ amickiewicz@gumed.edu.pl
}
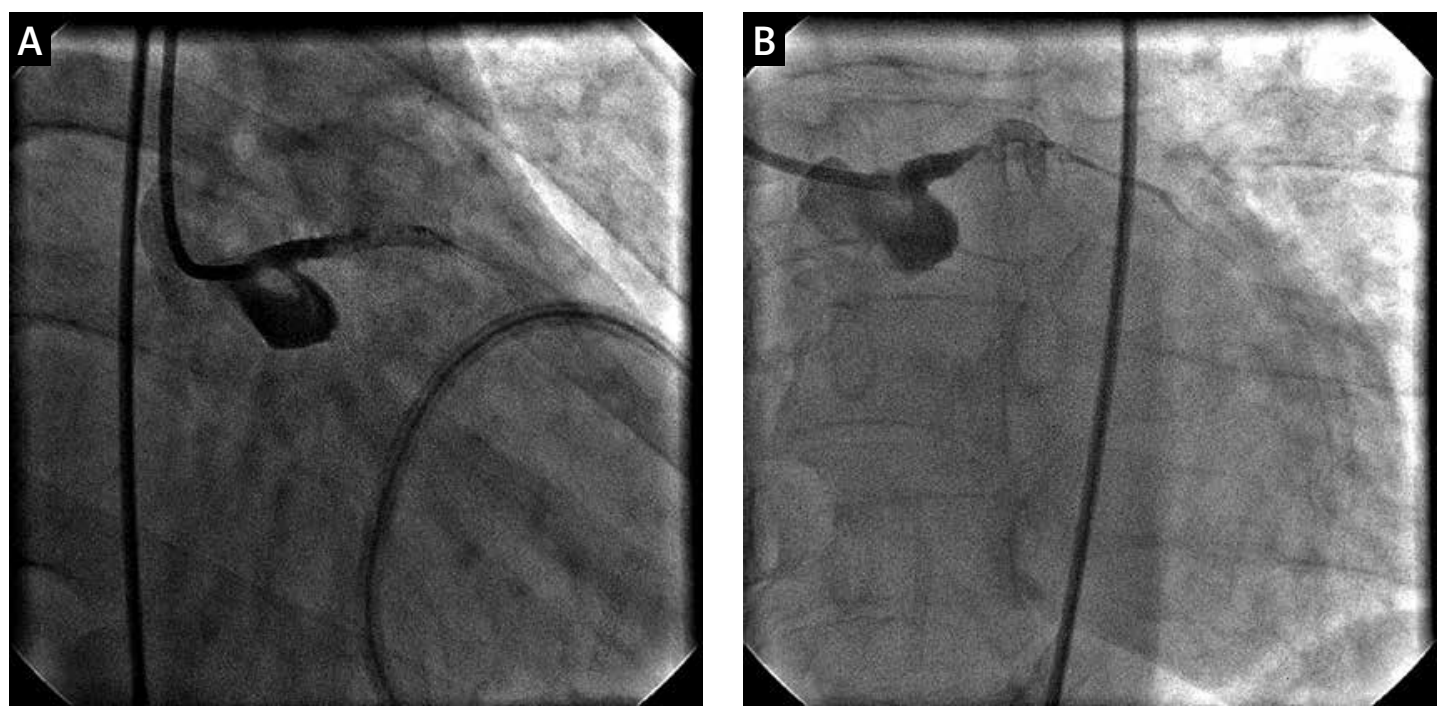

Figure 1. Coronary angiography: left main coronary artery occluded by stent thrombosis 


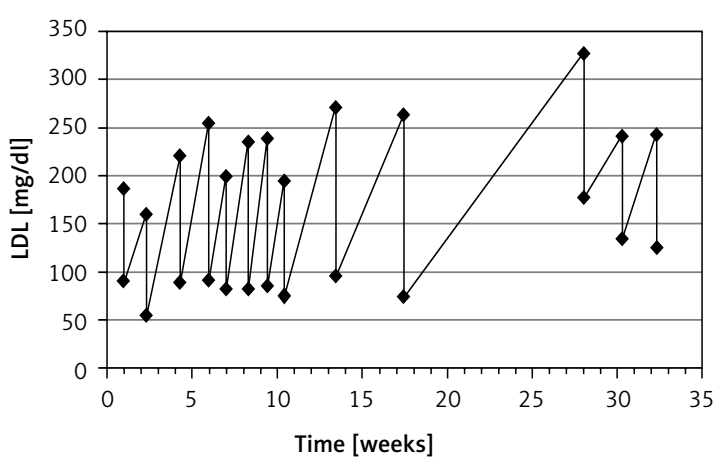

Figure 2. LDL-C concentrations before and after apheresis sessions

The coronary angiography at admission revealed a stent thrombosis in the left main coronary artery and a successful thrombectomy and balloon angioplasty was performed (Figure $1 \mathrm{~A}-\mathrm{B}$ ). Nevertheless, the patient developed cardiogenic shock followed by chronic heart failure with low left ventricular ejection fraction (23\%). Based on additional laboratory tests, resistance to aspirin was diagnosed. A treatment using acetylsalicylic acid in high doses (300 mg daily), ticlopidine, bisoprolol, ramipril, spironolactone, furosemide, ezetimibe and rosuvastatin was prescribed. Despite maximal doses of rosuvastatin $40 \mathrm{mg} /$ day and ezetimibe $10 \mathrm{mg} /$ day, the lowest observed LDL-C level was $181 \mathrm{mg} / \mathrm{dl}$. Systematic weekly/biweekly cascade lipoprotein filtration was started. The treatment was well tolerated and the only side effects observed were hypocalcemia and mild hypotension.

The average LDL-C levels before and after treatment were $233 \pm 43 \mathrm{mg} / \mathrm{dl}$ and $96.92 \pm 31.8 \mathrm{mg} /$ $\mathrm{dl}$ respectively (Figure 2 ). The mean acute LDL-C reduction of all apheresis sessions was 58.73 $\pm 8.71 \%$. Cascade filtration also decreases the level of the clotting factor fibrinogen resulting in a reduction of thrombosis risk. During the last ten months of LDL apheresis therapy, no clinical or angiographic progression of coronary artery disease was noted.

The most important factors determining the clinical course of $\mathrm{FH}$ are early initiation of treatment and a low interval mean LDL cholesterol concentration. In the described case, earlier LDL apheresis treatment could have prevented the major cardiovascular events leading to congestive heart failure. Fortunately it was not too late for this patient, because acute coronary syndrome was no longer observed after initiation of LDL apheresis treatment. We conclude that it was due to reduction of the clotting factor fibrinogen and thrombosis risk. Only selected methods of apheresis, such as the described cascade filtration, are able to remove fibrinogen.

In conclusion, our report supports the view that long-term reductions of LDL cholesterol and fibrinogen concentrations together with the pleiotropic effects significantly reduce cardiovascular risk and improve the quality of life of those with $\mathrm{FH}[6,7]$. LDL apheresis remains an underutilized option for $\mathrm{FH}$ patients with an uncontrolled high LDL-C level [5].

\section{Conflict of interest}

The authors declare no conflict of interest.

\section{References}

1. Nordestgaard BG, Chapman MJ, Humphries SE, et al. Familial hypercholesterolaemia is underdiagnosed and undertreated in the general population: guidance for clinicians to prevent coronary heart disease: Consensus Statement of the European Atherosclerosis Society. Eur Heart J 2013; 34: 3478-90.

2. Cicero AF, Derosa G, Maffioli P, Reggi A, Grandi E, Borghi C. Influence of metabolic syndrome superposition on familial combined hyperlipoproteinemia cardiovascular complication rate. Arch Med Sci 2013; 9: 238-42.

3. Myśliwiec $M$, Walczak $M$, Małecka-Tendera $E$, et al. Management of familial hypercholesterolemia in children and adolescents. Position paper of the Polish Lipid Expert Forum. J Clin Lipidol 2014; 8: 173-80.

4. Rynkiewicz A, Cybulska B, Banach M, et al. Management of familial heterozygous hypercholesterolemia: position paper of the Polish Lipid Expert Forum. J Clin Lipidol 2013; 7: 217-21.

5. Vishwanath R, Hemphill LC. Familial hypercholesterolemia and estimation of US patients eligible for low-density lipoprotein apheresis after maximally tolerated lipid-lowering therapy. J Clin Lipidol 2014; 8: 18-28.

6. Winters JL. Lipid apheresis, indications, and principles. J Clin Apher 2011; 26: 269-75.

7. Thompson GR, Catapano A, Saheb S, et al. Severe hypercholesterolaemia: therapeutic goals and eligibility criteria for LDL apheresis in Europe. Curr Opin Lipidol 2010; 21: 492-8. 